\title{
WHY NO TRANSLATION?
}

\author{
YAO SHEN \\ University of Michigan
}

The use of translation, either word-for-word or expression-for-expression, is often found in the teaching of a foreign language. It is also frequently regarded as an easy short-cut to attain command of the language to be learned. Teachers who have had practical up-to-date linguistic training, however, do not find it to be an entirely satisfactory technique. For the mastery of a foreign language involves more than the mere association of meaning carried by a word in the native language with that carried by another word in a foreign language. Every language is a closely and arbitrarily knitted mechanism composed of sounds and sound sequences, grammatical devices, and vocabulary items, and the details involved in this intricate relationship and the inter-play among these units are fairly rigid and limited, and vary from language to language. In other words, to memorize all the entries in a bi-lingual dictionary will not enable a person to speak a foreign language. There are essential linguistic features that lie outside the realm of lexical equivalents, such as the use of word order in English to distinguish certain statements from certain questions, the presence of one or more words functioning as a structural signal, the use of specific expressions which may have equivalents in lexical meaning in another language but which are used differently according to the social patterns or behavior of the people who speak the language. These and numerous other devices cannot be brought about by either word-for-word or expression-for-expression translation, and the purpose of this article is to use a few examples to show that translation is not an adequate technique in the teaching of a foreign language.

Every language uses certain devices to convey meaning. The same device may be used by various languages. For example, English and Chinese both use word order as a pattern to indicate the direction of action. The actor and the goal in 
the following sentences are distinguished by the position they occupy. Words that occupy position one in the chart below are usually recognized as the actor of the sentences, and words that occupy position three are generally regarded as the goal.

Chart I

\begin{tabular}{|l|l|l|l|}
\hline & position one & position three \\
\hline English & $\begin{array}{l}\text { The father } \\
\text { The child }\end{array}$ & $\begin{array}{l}\text { sees } \\
\text { sees }\end{array}$ & $\begin{array}{l}\text { the child } \\
\text { the father }\end{array}$ \\
\hline Chinese & $\begin{array}{l}\text { father } \\
\text { fùchin } \\
\text { (child } \\
\text { háidz }\end{array}$ & $\begin{array}{l}\text { see } \\
\text { kànjian } \\
\text { see } \\
\text { kànjian }\end{array}$ & $\begin{array}{l}\text { child) } \\
\text { háidz } \\
\text { father) } \\
\text { fùchin }\end{array}$ \\
\hline
\end{tabular}

Languages that use the same device do not necessarily have all the details in common. The following is an illustration: English and Chinese both may add a function word to a statement to form a question, but the position of the function word may be different, such as the position of do and ma in the given sentences below.

\section{Chart II}

\begin{tabular}{|c|c|c|c|c|c|}
\hline \multicolumn{2}{|r|}{ English } & \multicolumn{4}{|c|}{ Chinese } \\
\hline Do & $\begin{array}{l}\text { You want a book } \\
\text { you want a book }\end{array}$ & $\begin{array}{l}\text { (You } \\
\text { nǐ } \\
\text { nǐ }\end{array}$ & $\begin{array}{l}\text { want } \\
\text { iàu } \\
\text { iàu }\end{array}$ & $\begin{array}{l}\text { book) } \\
\text { shū } \\
\text { shū }\end{array}$ & $\mathrm{ma}$ \\
\hline
\end{tabular}

Furthermore, while one language may use word order, another may use something else. For example: English uses word order to indicate the difference between a statement and a question while Chinese uses the function word ma added to a statement to indicate a question. 


\section{WHY NO TRANSLATION?}

English:

$\begin{array}{lll}1 & 2 & \\ \text { This } & \text { is a book } \\ 2 & 1 & \\ \text { Is } & \text { this a book }\end{array}$

Chinese:

$\begin{array}{llll}\text { (This } & \text { is } & \text { book) } & \\ 1 & 2 & & \\ \text { jèi } & \text { shr̀ } & \text { shũ } & \\ 1 & 2 & & \\ \text { jèi } & \text { shr̀ } & \text { shū } & \text { ma }\end{array}$

There are also linguistic features that are found in one language but that are not found in another language. Two examples are given below. The first example illustrates that Chinese uses a noun auxiliary, in this case, benn, between the number and the noun, and English does not. The second example shows that English uses a function word, in this case do, plus the negative function word, not, to formulate the negative, and Chinese uses the negative function word, bù , alone.

\section{Example 1}

English: a book Chinese: I bĕn sha

\section{Example 2}

English: They do not come Chinese: tāmen bù lái

To translate such grammatical devices is not a rewarding practice, and yet the learning of such devices is necessary if one is to master the foreign language and speak it effectively.

Individual words usually carry more than one meaning. The total number of meanings a word carries in one language seldom coincides with all the meanings of a word in another language. The following is only one illustration. But the principle it illustrates is applicable to other words in other languages.

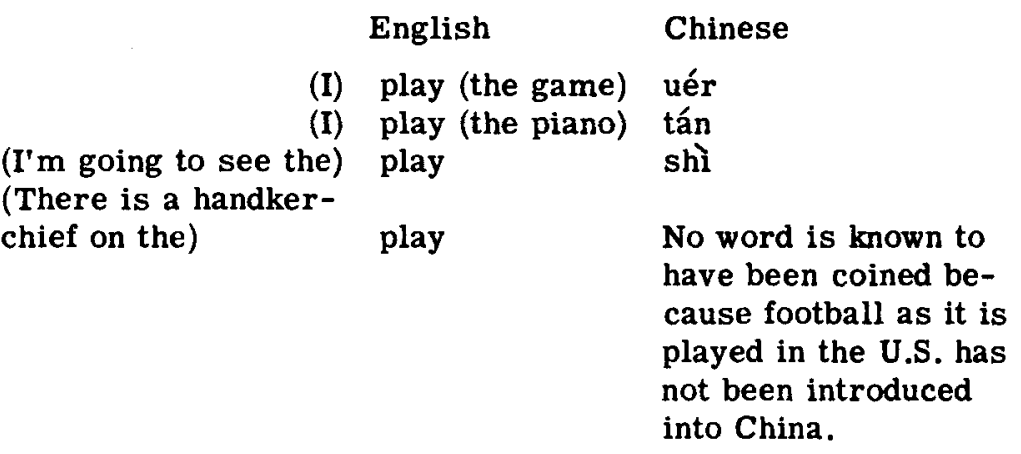




\section{YAO SHEN}

Words in one language which share one or more meanings with words in another language often function grammatically in different ways. Two examples are given with one of the possible meanings of a word in English equivalent to only one meaning of the word in Chinese.

Example 1

English: (one) book

Chinese: (i bĕn) shū

(two) books

(liăng běn) shü

This example shows that the addition of / $/$ is used in English to indicate more than one book while sho remains the same in form.

Example 2

English:

large

small

many

few
Chinese:

dà

shiău

duō

shău

The four English words listed above are given four equivalents in Chinese. They are equivalent in one meaning only. They have other meanings in which they are not equivalent, and their grammatical function is different also. The given English words may not be used as the entire predicate of the sentences while the Chinese words can. Thus sentences 1-4 in Chart III below are equivalent to sentences $5-8$ in the same chart in usage, but they are not equivalents in word-for-word translation. If word-for-word translation is used, the sentences with the same numbers in Charts III and IV would appear to be the same. The situations in which the sentences are used, however, are different. Sentences 5-8 in Chart III and sentences 1-4 in Chart IV are different in meaning according to native speakers. Sentences 5-8 in Chart IV are not used by native speakers to mean sentences 1-4 in Chart III. 


\section{WHY NO TRANSLATION?}

\section{Chart III}

\begin{tabular}{|c|c|c|c|}
\hline & & subject & predicate \\
\hline English & $\begin{array}{l}1 \\
2 \\
3 \\
4\end{array}$ & $\begin{array}{l}\text { Books } \\
\text { Books } \\
\text { (Books } \\
\text { (Books }\end{array}$ & $\begin{array}{l}\text { are large } \\
\text { are small } \\
\text { are many) } \\
\text { are few) }\end{array}$ \\
\hline Chinese & $\begin{array}{l}5 \\
6 \\
7 \\
8\end{array}$ & $\begin{array}{l}\text { shū } \\
\text { shū } \\
\text { shū } \\
\text { shū }\end{array}$ & $\begin{array}{l}\text { dà } \\
\text { shiău } \\
\text { duō } \\
\text { shău }\end{array}$ \\
\hline
\end{tabular}

Chart IV

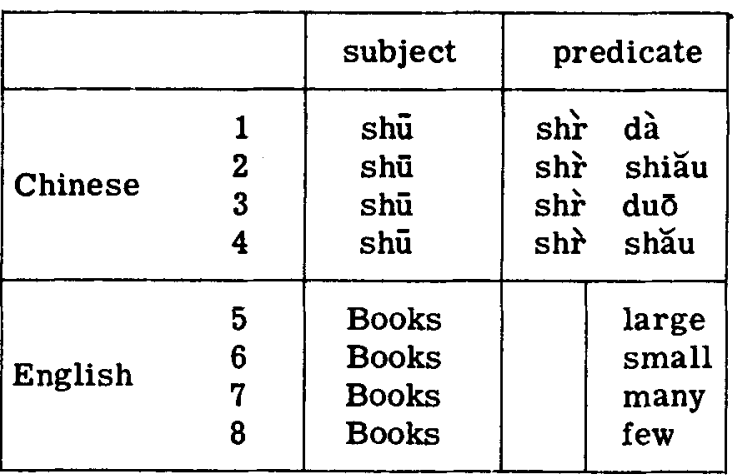

Further analysis will show that these same eight words are subject to other grammatical restrictions. One of them is that large, small, many, few, dà, shiău may be used as single premodifiers of such words as book, books, shū, etc., while duo and shău usually are not as indicated in the chart below. 


\section{YAO SHEN}

\section{Chart V}

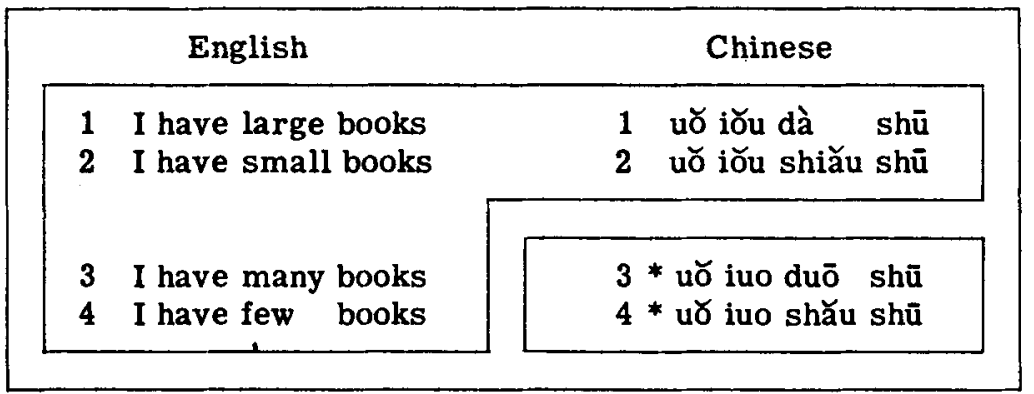

The asterisk, *, indicates that the form is not used by a native speaker.

Finally, each utterance has a different meaning depending upon the situation. Even within the same language, the same utterance has different significance. For example, in English, when a friend says, "How are you?" the answer is not "I have a bad cold" or "I have a nagging headache"; it is "Very well, thank you" even though there might be a cold or a headache at the moment. If we should tell our friend about our complaints, quite possibly he will feel imposed upon, because he meant only to greet us. However; when one goes to see a physician because of a bad cold or a nagging headache, and when the physician asks the patient, "How are you?" if the answer is "Very well, thank you" the physician will probably wonder why the patient goes to see him at all. In other words, utterances are used differently according to the cultural patterns of society. Meanings of utterances vary from situation to situation and from culture to culture. In different situations and in different communities similar utterances may describe a different range of situations. For example, in the situations given below, the English and the Chinese responses are fairly different. 


\section{WHY NO TRANSLATION?}

Situation 1: An interesting book is published

A: I like the book you wrote.

B: (English response) Thank you. I'm glad you like it. (Chinese response) jiàn shiàu (It deserves only to be laughed at.)

Situation 2: A person speaks English very well.

A: You speak English very well.

B: (English response) Thank you.

(Chinese response) bù hău (No good.)

Situation 3: There was a successful party.

A: Your party was a success.

B: (English response) Thank you. I'm glad you could come.

(Chinese response) dài màn (I was not able to be as courteous and thoughtful to you as I would like to and should be.)

It is not that the English speaker lacks sense of modesty; he is grateful for the appreciation. It is not that the Chinese speaker is constantly disagreeing; it is within his pattern of culture that he speak with modesty. In other words, the above responses in each case are culturally equivalent but not lexically equivalent. Therefore in learning the meanings of words and expressions to obtain command of a foreign language, it is more important to learn what to say under particular circumstances than to translate either word-for-word or expression-for-expression. As Charles C. Fries says, "A thorough mastery of a language for practical communication with real understanding demands a systematic observation and recording of many features of the precise situations in which the varied sentences are used." 1

${ }^{i}$ Teaching and Learning English as a Foreign Language, University of Michigan Press, 1947, p. 57. 